\title{
Educational And Financial Impact Of Technology On Workforce Development
}

Paul J. Carruth, Southeastern Louisiana University, USA

Ann K. Carruth, Southeastern Louisiana University, USA

\begin{abstract}
In the current evolving economic environment, developing and implementing an effective workforce to improve the skills and capability of employees are seen as central to improving individual and organizational performance and competitiveness. The availability of online education in universities as well as the work place has significantly increased during the past decade. This paper summarizes and addresses the current research, trends and future prospects of e-learning as it relates to the awarding of higher educational degrees and private sector workforce development.
\end{abstract}

Keywords: E-Learning; Workforce Development; Higher Education; Online Education

\section{INTRODUCTION}

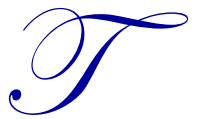

echnological innovation has rapidly transformed the way people are being educated and trained, while at the same time, it has equally become a key tool in building business capacity and increasing workforce skills and competencies. Described as the new Learning Revolution, the internet has created a borderless digital platform and a new economy known as e-learning. As John T. Chambers, President and CEO of Cisco Systems recently stated, "The next big killer application for the Internet is going to be education. And education over the Internet is going to be so big it is going to make e-mail look like a rounding error." (Clowes, 2000).

E-learning, defined as education and training which takes place partially or entirely over the internet, has already become an integral systemic part of practices and policies designed to educate, prepare, and support both students and future workers. Modern day use has gained significant momentum in the past few years and now represents an expansive and widely used Learning Platform (LP) for broadening, connecting, and enriching traditional methods. The power comes from the opportunity to leverage and transform basic tenets of learning by replacing traditional one-size fits-all approaches to instruction and customizing content to meet individual needs and learning styles (Pantazis, 2002).

The American Council of Education (ACE) (Kerkman, 2004) reports that e-learning continues to evolve exponentially in how we educate individuals and increasingly employers. Given the fact that many technology companies themselves are unsure of the knowledge and skills their workers will need by 2020, several experts believe that e-learning is a promising solution to the increasing need for rapid, flexible training. However, it is both largely unknown and academically debated how e-learning will formally impact secondary and vocational education. Recent data findings suggests that it is measurably effective for primary K-12 education as an alternative to public schools for obtaining diplomas and augmenting home schooling. However, many experts believe that this will not be the case for secondary and graduate education (Allen \& Seaman, 2008). Rather, many researchers believe e-learning will be used to supplement, compliment, and provide alternatives to students without replacing the college experience where the majority of secondary education time spent will continue to be face-to-face between faculty and students.

Although there are many proponents of e-learning, there is also skepticism and valid questions regarding its relevance to organizational knowledge, its scalability, and its effectiveness in the awarding of primary, secondary 
and vocational degrees and certifications. In many ways, e-learning is so new that peer review research and studies to quantitatively measure and evaluate impact and effectiveness have yet to be conducted on a large scale basis. Those which have are often limited by design, methodology, and small sample sizes (Allen \& Seaman, 2003). While successful economies have always depended on a skilled and knowledgeable workforce, today's rate of change in production processes and workplace technology is requiring more ongoing training and retraining than in previous years. Researchers agree that these new tools will continue to be directly related to future business earnings and sustainability, and will be necessary for workers to remain competitive in an ever-changing global economy. In fact, historically, very few emerging markets or industries have been classified as unstoppable juggernauts in size or scope. However, if analysts and current trends prove correct e-learning will establish itself as the new juggernaut of training and development (Kayla, 2010a).

\section{THE E-LEARNING IMPACT}

Today's global business market for producing and providing e-learning is estimated at more than $\$ 53$ billion annually. Although the largest market share continues to be concentrated in the United States, the strongest growth segment is in Asia and expenditures differ within and between countries (European Commission, 2000). Today, technology based learning represents a wide range of business growth and educational opportunities. These include distance education, Computer-Based Training (CBT), Web-Based Training (WBT), Internet-based Training (IBT), courseware delivery and online testing. In essence, it represents the total integration of multimedia, instructor-led, and real-time facilitating within a very human and collaborative environment (Tavangarian, et al., 2004). Although e-learning is not universally suited to all learning styles, especially in older populations (Ally \& Fahy, 2002), there is increasing recognition that it can provide one potential route by which to overturn the twin barriers of lack of time and geographical isolation encountered by many learners (Sharpe, Benfield, Roberts \& Francis, 2006).

Research shows that in 2005, 33\% of American training hours were delivered using some form of technology; by 2011 it had increased to $48 \%$ and is expected to continue a steady upward trajectory (Blezu, 2008). In their 2007 State of the Industry Report, ASTD reported that e-learning is becoming more widely used for several reasons. Among them are the higher fees being charged for instructor-led classes coupled with a growing reluctance in having employees miss work in order to attend trainings (ASTD, 2012). In 2002, the U.S. Department of Defense's Advanced Distribute Learning Initiative formed a collaboration of government, academia, and the private sector to develop a web-based and open architectural forum for online learning. The result of this collaboration was the establishment of a virtual system which features a comprehensive suite of e-learning capabilities that enable interoperability, accessibility, and the reuse of web-based learning content.

Available research demonstrates cost-savings and measurable benefits of this virtual system in its potential for broadening access to high-quality education and training. However, studies are increasingly showing that it is not a panacea nor is it appropriate in all learning systems and settings. Rather it is being shown as a viable opportunity for enhancing and improving existing educational systems and also increasing workforce capacity and efficiency. The future will likely consist of a blended or hybrid approach involving a combination of traditional classroom instruction and e-learning. And although this new learning juggernaut is very real, it lies with researchers, academics, and front end users to determine its future breadth, scope and reliability.

\section{E-LEARNING AND STUDENT EDUCATION}

By 1994 the first online high school had been founded, along with criteria for evaluating product content of technology-based courses which were portable, replicable, scalable, and affordable with high probability of longterm cost-effectiveness. Virtual education has become the new norm in education history and arguably one of the most powerful tools available to the growing need for education (Aleksander, 2012). Evolving technologies in education have created asynchronous instruction (a student-centered and project-based learning environment) as an appealing alternative to traditional synchronous instruction (classroom based with instructors delivering lectures) and has gained increased interest among academic fields (Graziadei, et al., 1997). Modern online learning includes offerings that run the gamut from conventional didactic lectures or textbook similar information delivered over the web to internet-based collaborative role-playing in social simulations as well as highly interactive multiplayer strategy games. 
Continuing Education Units (CEU) were one of the first on-line opportunities offered, where today CEU courses are available for virtually every occupation which requires CEUs annually. Today, many teachers, instructors, trainers, counselors, social and health workers are able to complete most, if not all of their credits online, often at much lower costs than attending a conference or training seminar which takes time, money, and travel to acquire (Sharpe, Benfield, Roberts \& Francis, 2006). For the majority of first year college students, enrolling in an online course is the first time they experience e-learning, especially since these skills were not needed for face- toface classroom instruction as high-school students (Bates \& Poole, 2003). Increasing numbers of universities are implementing online courses for students. In 2009, colleges reported the highest-ever annual increase in online enrollment-5.6 million students, representing more than 29\% of the total college and university enrollment, according to an annual report by the Sloan Consortium which annually surveys more than 2,600 higher-education institutions (Allen \& Seaman, 2010). Further, the report indicates that larger institutions tend to have greater proportion of online courses than smaller universities.

Many reasons account for the increasing growth of online courses and programs. Green (2010) reported that colleges and universities, looking for ways to lower costs, are motivated to develop and grow their online programs. Forty-two percent of the ITC Survey participants identified the economic downturn as a reason for recent growth in online learning at community colleges (Trends in e-learning: Tracking the Impact of e-earning at Community Colleges, 2010). Research showed that almost $75 \%$ of public colleges indicated online education is critical to their long-term strategies (Kayla, 2010b). While research has demonstrated that students in an online environment can succeed in coursework as well as those enrolled in traditional face-to-face instruction, the examination of online teaching strategies and formats in relation to quality and depth of learning is lacking. According to the literature, very little is known about mediating variables that measurably promote or hinder learning success in an online environment (Sharpe, Benfield, Roberts \& Francis, 2006). Institutions see little indication that student interest in online learning will subside. This is especially true when state initiatives promote statewide strategies to save tax dollars and to reach more students. Increasingly, more high schools are offering incentives for online education. For example, students who earn the ACHIEVE scholarship in Minnesota would be given a $\$ 150$ bonus if they complete an online course while in high school (Young, 2008).

Technologies that support online learning are more reliable and robust than they were a decade ago. This has led to alternative formats for delivery. Massive Open Online Courses (MOOC) are a new form of on-line distance education courses which are open and free. These courses often draw participation from tens of thousands of students around the world (Ally \& Fahy, 2012). Most MOOCs do not provide students with academic credit towards a degree, but that could be changing as organizations study how to evaluate students, grade them, and award credits. Universities around the United States have rushed to join alliances and create open online courses of their own (The Year of the MOOC, 2012). Several companies are competing to lead the movement, including two of the biggest providers, Coursera and edX (Kenny, 2012). For example, Coursera is a for-profit company launched in 2012 by two Stanford University professors and includes 33 partners, including Duke, Princeton, Columbia, and the Universities of Florida, Maryland, Michigan and Virginia. Also established in 2012, edX is a MOOC that was started last year by MIT and Harvard and includes the University of California Berkeley and the University of Texas system (Charlotte Observer, 2013). However, effective e-learning for student populations is highly dependent on discipline, time management, and commitment to completing work and assignments. And although a worthy alternative to America's fledging K-12 public education system (n.a. Disadvantage, 2013), concerns include student course completion rates, successfully passing exams, and being awarded diplomas. It further demands that a student have readily available access to both a computer and internet that is efficient and consistent (Mason \& Kaye, 1989).

One unique challenge to online education is the ability to supervise, track, and verify student performance. Issues like cheating, plagiarism, and students enrolling multiple times in order to increase or perfect scores are very real and tangible concerns. Combating academic dishonesty has been and will continue to be difficult to manage and control. However, innovation is producing methods and implementing techniques such as using keystroke biometrics to identify students or requiring students to present an ID before they take a test as well as virtual camera monitoring (Youngberg, 2012). In 2007, the Higher Education Academy, a United Kingdom academic body commissioned a series of studies intended to inform higher education policy and practice and to contribute to the ongoing discourse on improving the student learning experience. Among their findings was the need for e-learning to successfully decentralize the delivery of education - both to workplaces and homes - in order to become embedded 
into an individual's everyday work and life-style. Another important consideration for e-learning success, in tandem with concerns of effectiveness and economy, is acceptability of the delivery mode. If there is little to separate faceto-face and e-learning modalities with regard to impact and cost, then the quality of the student experience becomes paramount (Harun, 2001). As academics continue to meet the needs of new and future students, understanding and teaching to generational and life experience differences will be critical.

\section{PRIVATE INDUSTRY AND E-LEARNING}

In 1999, corporate America alone spent $\$ 63$ billion on educating and training its workforce. Of that spending, e-learning accounted for $\$ 3$ billion and was rated as the fastest-growing segment of the market. By 2003 it had grown to $\$ 11.4$ billion. Last year, 70 million people received training and education on the internet. In 2006, U.S. organizations spent nearly $\$ 130$ billion on employee learning and development (Bates, 2011). What began as basic Information Technology (IT) training in the business sector has quickly made its way into management, sales, marketing, customer service, and professional development. This multimedia approach to workforce development has ten major advantages (International Data Corporation):

1. Real-time learning

2. Learner-centric training

3. Attract, train and retain

4. Personalized individual training

5. Ownership and empowerment

6. Simulation

7. Collaboration

8. Anytime and anywhere

9. Cost-effective

10. Quantifiable Return on Investment (ROI)

E-learning is now being effectively measured in terms of knowledge gain and retention, which has become the newest focal business selling-point. Companies will be able to establish systems that can track progress, report results, and specify additional subject matter for continued success. This is where Return On Investment (ROI) will be recognized by both the employer and employee. It also suggests that it will identify in the future which corporations are serious about attracting, training, and retaining future workforces. Increasingly, e-learning is being used by companies to teach skills, develop talent, and provide information and training in a cheaper and more time efficient manner while being available and accessible 24/7 from anywhere in the world. Research suggests that elearning can contribute to workforce development in three distinct ways:

- $\quad$ Overcoming challenges associated with gaining access to education.

- $\quad$ Overcoming motivation problems amongst worker/learners.

- Overcoming the negative legacies of prior educational experiences.

It is projected that eventually, training for nearly every job in the world will be available over the internet with the real change in business practices being the acceptance that employee knowledge represents the future's competitive edge. Paradoxically, worker development and investment has also been the most neglected and ignored opportunity in today's competitive business industry. Learning has not only become mobile over the internet, but is also now mobile with each employee. A study by the ROI Institute notes that when it comes to learning and development, Chief Executive Officers primarily want to know:

- What is the expected impact on business results?

- What is the expected return on investment?

These questions are all the more critical now, as companies look for ways to rebuild strength and gain a competitive advantage in what has become the ongoing recovery of the national and global economy. Another recently conducted survey by the ROI Institute targeted Fortune 500 CEOs and the top 50 privately held American firms (Oracle, 2012). With a sample of more than 450 businesses, investments into e-learning by these companies 
ranged from $\$ 10$ to $\$ 640$ million with a mean average of $\$ 138$ million. The majority (76\%) reported investing significant resources into this emerging field, while $20 \%$ said they only invest the minimum and $4 \%$ reported that they try to avoid these investments and costs. Finally, highest on the "planning to add" list over the next 12-months included mobile learning as the number one spot, followed by development tools and social networks as third. In another study of 240 organizations, almost half of all respondents (46\%) reported using classrooms for training, 27\% e-learning, 19\% blended, and 10\% other (Masie, nd). Additionally, shoring up the leadership ranks in corporations continue to be the top driver of training investments, cited by $51 \%$ of companies surveyed. Contrary to conventional wisdom, employee retention ranks dead last. Thus the question remains, Does e-learning actually improve employee performance? Today some of the only available metrics are anecdotal and data collection efforts have been focused on count data such as usage rates and hours instead of methodologically driven and experimentally designed evaluations (Kranz, 2008). And although this reflects people's level of interest, it sheds little light on whether or not the learning is actually effective and measurable. Thus, only $16 \%$ of firms cited retaining key performers as their top talent challenge in 2007.

At General Motors University Online, employees can create individual development plans, track their individual training histories, and use Web-based tools to align their training with development plans in 16 functional company areas. GMU is serving 88,000 managerial, professional, and technical employees globally. For every $\$ 1$ of e-learning that the company offers, it estimates that it saves $\$ 2$ in traditional class-room tuition, and an additional $\$ 1$ for travel time or lost personnel time. Regarding the cost/benefit of online education, Pantzis (2002) noted in his research, "It is a question that needs to be asked and must be studied in future research." Small business owners, entrepreneurs, executives, and managers face the challenge of not only recognizing when change is coming, but where it's coming from, and how it will affect their business operations. Some visionary leaders are quick to see emerging markets and industries. But in today's ever-changing and unknown future, e-learning will alter significantly the way the business world operates into the future. In addition to facing the challenge of recognizing change, business leaders must also know how to attract, train and retain knowledgeable workers. In the past, this has been viewed as a very high expense to companies, a liability, rather than a necessity.

\section{E-LEARNING AND WORKFORCE DEVELOPMENT}

Today, the business world has three very fundamental concerns and weaknesses: attracting, training, and retaining intellectual capital. The workforces of the new millennium are increasingly free agents and job hoppers who offer portable knowledge and are lifelong learners (Brockbank, nd). While successful economies have always depended on a skilled workforce, today's rate of change in production processes and technology requires much more training and retraining on the job than it has in the past. The need for organizations to promote and capture learning at the individual, team, and organizational levels has fueled considerable interest in the concept of the learning organization. At an industry level, e-learning can also address problems as diverse as industry fragmentation and skill shortages but is highly tied to and dependent upon the nature of the learning environment and the agents who provide those services. Recent studies found that upwards of $70 \%$ of companies reported issues and challenges in being able to unlock what are often idle learning resources held within discrete systems whereby access, consistency, and constant updating of content and systems is ongoing.

Because e-learning has the potential to significantly improve workforce development, the American Society for Training and Development (ASTD) and the National Governors' Association (NGA) examined how elearning can equip workers with the skills needed to succeed. The culmination of this effort makes the social and economic case for creating a sustainable e-learning environment for America's workforce and identifies priority areas for action for the public and private sectors. According to Fortune Magazine, training that typically would take 6 to 9 months can be compressed to 2 to 3 weeks, thereby guaranteeing faster time-to-market for products. After the initial infrastructure and development costs are met, the marginal cost of serving additional students is close to zero. For example, Cisco Systems' e-learning manufacturing programs have produced savings of \$1 million per quarter, producing an $80 \%$ increase in speed to competence. 


\section{THE FUTURE OF E-LEARNING AHEAD}

It goes without saying that the most basic prerequisite for successful e-learning is the provision of appropriate technology. But the infrastructure needed is more than computer hardware and software. There is also the need for proper staffing to support this new learning medium. At a time when public concern persists about the economic disparities among different segments of the population, e-learning holds the potential to diminish the skills and income gaps by expanding just-in-time access to high-quality training opportunities. This in turn can contribute to income growth at all levels. E-learning can help create unprecedented opportunity, productivity, and prosperity for individuals and organizations. However, it is not a panacea for addressing the continuous challenge of increasing the performance and capabilities of the workforce. Traditional, institution-based approaches to assessment and certification are not well suited to an e-learning world in which the focus turns from a record of classes taken and degrees received, to measures of what an individual actually knows and is able to do.

\section{AUTHOR INFORMATION}

Paul J. Carruth, Ph.D., CPA is a Professor of Accounting at Southeastern Louisiana University. He can be reached at Southeastern Louisiana University, Department of Accounting, SLU Box 10468, Hammond, LA. He has previously published articles about workforce development issues in business. Paul Carruth has taught accounting at Southeastern Louisiana University for over 30 years. As professor, his program of research includes workforce training needs and cost accounting related to healthcare trends. E-mail: pcarruth@selu.edu (Corresponding author)

Ann K. Carruth, DNS, RN is a Professor of Nursing and Dean at Southeastern Louisiana University. She can be reached at Southeastern Louisiana University, School of Nursing \& Health Sciences, SLU Box 10781, Hammond, LA 70402. She too has written about e-learning issues. Ann Carruth is currently dean of the College of Nursing and Health Sciences at Southeastern Louisiana University. Her role as an administrator includes designing innovative curricula that address workforce needs in the southeast region of Louisiana. E-mail: acarruth@ selu.edu

\section{REFERENCES}

1. Allen, I.E., \& Seaman, J. (2003). Sizing the Opportunity: The Quality and Extent of Online Education in the United States. Wellesley, MA: The Sloan Consortium.

2. Allen, I.E., \& Seaman, J. (2008). Staying the Course: Online Education in the United States.

3. Allen, I.E., \& Seaman, J. (2010). Class Differences: Online Education in the United States, 2010. Newburyport, MA: Babson Survey Research Group and The Sloan Consortium.

4. Aleksander A. (2012). The impact of ICT on Education and Performance and its Efficiency in Selected EU and OECD countries: A Non-Parametric Analysis. MPRA Paper No. 39805.

5. Ally, M., \& Fahy, P. (2012). Information Sessions: Using Students' Learning Styles to Provide Support in Distance Education. Paper presented at the 18th Annual Conference on Distance Teaching and Learning, University of Madison, Wisconsin, $14-16$.

6. ASTD (2012). State of the Industry Report. http://www.astd.org

7. Bates, A., \& Poole, G. (2003). Effective Teaching and Technology in Higher Education, San Francisco: Jossey-Bass/Wiley.

8. Bates, T. (2011). Advice from Private Sector on Online Learning. The Midden.

9. Blezu, C. (2008). The Impact of e-learning in Education. MACMESE '08 Proceedings of the 10th WSEAS International Conference on Mathematical and Computational Methods in Science and Engineering. Pages 496-501. ISBN: 978-960-474-019-2.

10. Brockbank, B. (nd.). e-Learning and the e-Workforce. www.refresher.com

11. Charlotte Observer (2013). http://www.charlotteobserver.com/2013/01/19/3798851/in-a-duke-logic-classwith-180000.html\#storylink=cpy

12. Clowes, G. (2000). Next big killer app: Education. www.heartland.org/newsletter-article/2000/

13. Cramer Sweeney's web www.cramersweeney.com/cs_id/trainingblog/, Elliott Masie shared the Executive Summary results from his Learning Consortium's survey.

14. The Disadvantages of Online Learning (2013). Elearning Companion. N.p., n.d. Web. 
15. EC (2000). Communication from the Commission: E-Learning - Designing “Tejas at Niit” Tomorrow's Education. Brussels: European Commission.

16. E-Learning User Study: Corporate Segment. E-learning! And Government E-learning! Magazines. Research Advisory Group Report.

17. Graziadei, W.D., et al., (1997). Building Asynchronous and Synchronous Teaching-Learning Environments: Exploring a Course/Classroom Management System Solution. Horizon UNC Education Monograph.

18. Green, K. C. (2010). The Campus Computing Survey. Encino, CA: The Campus Computing Project. Retrieved from http://www.campuscomputing.net/2010-campus-computing-survey

19. Harun, M.H. (2001). Integrating e-Learning into the workplace. The Internet and Higher Education. 4 (34), 301-310.

20. International Data Corporation, Brockbank, http://www.refresher.com/aeworkforce.html

21. Kaya, T. (2010a). Enrollment in Online Courses Increases at the Highest Rate Ever. Wired CampusChronicle of Higher Education, November 10.

22. Kaya, T. (2010b). http://www.elearninglearning.com/2010/articulate/ebook/

23. Kenny, A. (2012). Online learning: enhancing nursing education? Journal of Advanced Nursing, 38 (2): 127-135.

24. Kerkman, L. (2004). Convenience of Online Education Attracts Midcareer Students. Chronicle of Philanthropy, 16(6), 11-12. Retrieved from Academic Search Premier Database.

25. Kranz, G. (2008). E-learning hits its stride. www.workforce.com

26. Mason, R., \& Kaye, A. (1989). Mindweave: Communication, Computers and Distance Education Oxford, UK: Pergamon Press.

27. Pantazis, C. (2002). Maximizing e-learning in the 21st Century Workforce. Public Personnel Management, 31(1), 21-26.

28. Sharpe, R., Benfield, G., Roberts, G. \& Francis, R. (2006). The Undergraduate Experience of Blended ELearning: A Review of UK Literature and Practice. York: Higher Education Academy.

29. Tavangarian, D., Leypold, M., et al. (2004). Is e-learning the Solution for Individual Learning? Journal of e-learning.

30. "The Year of the MOOC" (2012). Massive-open-online Courses Are Multiplying at a Rapid Pace. The New York Times.

31. Young, J. (2008, November 20). Minnesota state colleges plan to offer one-fourth of credits online by 2015. The Chronicle of Higher Education.

32. Youngberg, D. (2012). Why Online Education Won't Replace College-Yet. The Chronicle of Higher Education. 
NOTES 